\title{
The fate of groundwater: a lawyer's point of view
}

\author{
Dmitry Sivakov ${ }^{1}$, Yury Truntsevsky, ${ }^{1, *}$, Roman Osokin $^{2}$, Sergey Belyasov ${ }^{3}$, Oleg \\ Karpovich $^{4}$ \\ ${ }^{1}$ Institute of Legislation and Comparative Law under the Government of the Russian Federation, \\ Cheremushkinskaya str., 34, Moscow, 117218, Russia \\ ${ }^{2}$ Bauman Moscow State Technical University, Baumanskaya 2 St., 5/1, Moscow, 105005, Russia \\ ${ }^{3}$ Moscow Regional Institution of Higher Education "University for Humanities and Technologies", \\ Green St., 22, Orekhovo-Zuevo, Moscow region, 142611, Russia \\ ${ }^{4}$ Diplomatic Academy of Ministry of Foreign Affairs of the Russian Federation, Ostozhenka str., \\ 53/2, Moscow, 119021, Russia
}

\begin{abstract}
The study of the provisions of various branches of Russian law and practice of law enforcement (judicial), which in different ways express the complex legal status of subterranean water bodies. During the study process of the considered question the following general and private methods of scientific cognition of the real and objective reality were applied: dialectical, logical and legal, statistical, system analysis, specific sociological, and professional methods of research. The peculiarity of the authors' methodology is the use of data of natural science, as well as data of economic or technical properties, based on which legal ideas are developed. The comparative legal method of research is applied. The authors have analyzed, summarized, and synthesized the main approaches to the legal regulation of relations concerning groundwaters. The main provisions and proposals are compared with the domestic legislation and European Union law, its individual members (for example, Croatia). The example of the law of the state of Texas USA is given. Step by step, the legal status for the use and protection of subterranean water bodies has evolved into a qualitatively new phenomenon that absorbs all previous legal approaches and principles.
\end{abstract}

\section{Introduction}

Article 4 of the Federal Law of January 10, 2002, No. 7-FL «On Environmental Protection» contains the following norm - objects of environmental protection from pollution, depletion, degradation, damage, destruction and other negative impacts of economic and (or) other activities are components of the natural environment, natural objects, and natural complexes. In the early version of this article (No.26 of 24.11.2004), surface and groundwater were singled out among others.

The protection of subterranean water bodies is ensured by the provisions of water legislation and, in the conditions of their use, by subsoil legislation. Persons whose

*Corresponding author: truzev@yandex.ru 
activities have or may have a negative impact on the condition of subterranean water bodies are obliged to take measures to prevent pollution, contamination of subterranean water bodies and depletion of water, as well as to comply with the established standards of permissible impact on subterranean water bodies.

In particular, there should be no production and consumption waste disposal facilities, cemeteries, abattoirs, or other facilities having a negative impact on the state of groundwater on the water abstraction areas of subterranean water bodies that are used or can be used for drinking and domestic water supply.

If aquifers are uncovered during subsoil use, measures should be taken to protect subterranean water bodies. During design, construction, reconstruction, commissioning, operation of water abstraction facilities associated with the use of subterranean water bodies, measures should be taken to prevent the negative impact of such facilities on surface water bodies and other environmental objects (Art. 59 of the Water Code of the Russian Federation).

Underground water levels store up to $98 \%$ of the world's freshwater sources. They in turn supply $50 \%$ of all drinking water, $40 \%$ of them are used for industry and another $20 \%$ for agriculture.

Currently, groundwater is more interesting in the context of use than property (here are several applications: the source for direct consumption, for domestic and industrial use, irrigation, for the conservation of natural habitats (flora and fauna), for recreation, aesthetics, and fishing, for energy production, for transport, etc.).

When a disaster occurs, groundwater becomes something necessary for survival. For example, during the Great Hanshin-Awaji earthquake in Japan in 1995 and the Great East Japan Earthquake in 2011, many people survived by using groundwater from a public well in the neighborhood until a rescue team arrived.

Contamination of soil and groundwater, including drinking water, by oil products, is one of the most serious problems in oil and gas production regions.

Only $1 \mathrm{~m} 3$ of oil, getting into the soil, can contaminate the surface layer of groundwaters with an area of more than 5 thousand $\mathrm{m} 2$. There are few systematic statistical data on groundwater pollution. Available data show that the Middle $\mathrm{Ob}$ oil and gas province (Western Siberia) contains oil and oil products, phenols, and other contaminants typical for oil production in concentrations exceeding the maximum allowable concentrations (MPC).

Today, the main way of recycling mining waste continues to be its disposal in landfills owned by enterprises or the pumping of polluted waste into subterranean water sources, so the volume of their accumulation does not decrease.

\section{Methods}

In the process of research of the considered question, the following general and private methods of scientific cognition of the real and objective reality were applied: dialectical, logical and legal, statistical, system analysis, specific sociological and professional methods of research; comparative legal method.

There are two approaches to groundwater at legal science in Russia. Some authors believed that aquifers and deposits, as well as operations with them, fall under the subsoil law. Others insisted on the inclusion of groundwater in the state water fund, any operations with which (discharge, emissions) are subject to legal regulation of water legislation. These disputes remain to this day, and groundwater remains without sufficient attention from the legislator and enforcer which is the worst option.

As it was noted in the legal literature, it remains unclear up to what limits the rocks containing groundwater can be recognized as objects of property rights.

The authors have used scientific works on monitoring of the natural environment, 
modeling, and differentiation in ecology.

\section{Results}

According to Article 5 of the Water Code of the Russian Federation, the boundaries of subterranean water bodies are determined under the subsoil law. However, subsoil legislation is silent on this issue. This issue may seem irrelevant, since subsoil entirely, including underground residue, belong to one owner - the State. Therefore, subterranean water bodies seem to be lost in the total mass of state ownership of the subsoil. However, with the development of market relations in the field of natural resources management, subterranean water bodies may become the subject of the groundwater mining contract provided for in the projected, but not adopted mining legislation. In any case, it is necessary to protect groundwater from negative impacts from outside. To ensure such protection in law, it is necessary to have a conceptual understanding of the «surrounding» and «host» their rocks.

Groundwater is as if at the «crossroads» of water and mining industry statuses. This circumstance creates additional complexity in theoretical and practical aspects.

It should be noted that the current subsoil legislation uses the term «groundwater» rather than «subterranean water bodies». The reason is that the law considers groundwater to be an extractable resource rather than a natural formation in need of protection. Nevertheless, it is not an error to apply the term «water body» to groundwater basins and aquifers due to the norms of the Water Code of the Russian Federation.

Further, violation of the rules of protection of groundwater is considered by the legislator to be an administrative offense (Article 8.13 of the Code of Administrative Offences of the Russian Federation indicates a violation of the rules of protection of water bodies).

It should be noted that groundwater is the subject of legal regulation by the United Nations Economic Commission for Europe conventions. In particular, the Helsinki Convention not only requires that additional specific measures to prevent groundwater pollution be implemented, but also that the specificity and the particular vulnerability of groundwater be taken into account when developing management and protection measures (Annex III). Groundwater abstraction activities and groundwater artificial recharge schemes of a certain large enough volume require an environmental assessment and other procedures under the Convention on Environmental Impact Assessment in a Transboundary Context.

Directive 2006/118/EU of the European Parliament and of the Council of 12 December 2006 on protection against pollution and degradation:

- groundwater is a valuable natural resource and must, therefore, be protected from chemical contamination and damage. This is particularly important for groundwaterdependent ecosystems and for using groundwater for human water supply;

- groundwater is one of the most endangered and largest freshwater bodies in the European Union and a major source of drinking water for the general public in many regions;

- groundwater used for the abstraction of drinking water or intended for future use should be protected in such a way that the quality of such bodies does not deteriorate;

- to protect the environment in general and human health in particular, concentrations of hazardous pollutants in groundwater should be avoided, prevented, or reduced.

In Russia there is no special law on groundwater, as well as in other jurisdictions, so the general legislation on the management of subterranean water objects (in Latvia, for example, there is a general law of 2002 «On Water Resources Management»), can be configured as a «redundant legal structure». 
According to Articles 10.1, 19.1 of the Subsoil Law, groundwater is extracted for centralized drinking and domestic water supply based on a license for extraction of groundwater, while for technological needs this category of water is extracted under a technical project. The technical project for the development of mineral deposits also provides for measures to protect subterranean water bodies. The elimination of emergency and unusable wells as well as the conservation of unused boreholes are carried out by subsoil users following the project documentation for the elimination or conservation of these boreholes.

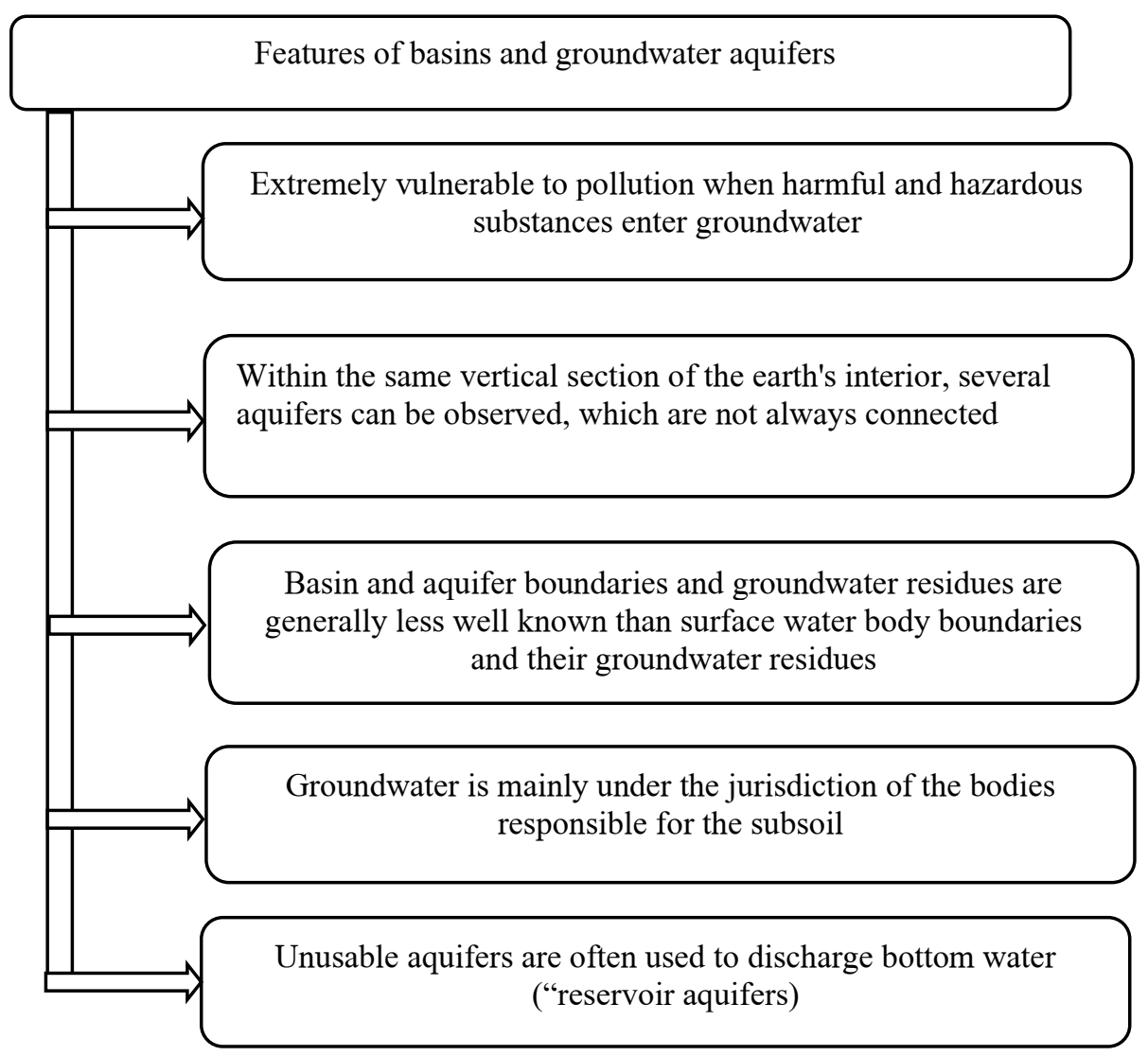

Fig. 1. Features of basins and groundwater aquifers.

At the same time, basins and groundwater aquifers differ from surface water bodies in their natural and economic characteristics as follows.

1) Subterranean water bodies, while protected by rock formations, are extremely vulnerable to contamination when harmful and hazardous substances enter the groundwater. Unlike rivers and flowing lakes, which neutralize pollution because of their mobility, static groundwater has been concealing pollution for centuries. For example, the environmental damage caused by the 1999 missile and bombs attacks on Yugoslavia concerns not only Danube waters, but also underground residue, especially those affected by the strikes.

2) Within the same vertical section of the earth's interior, several aquifers may be observed that are not always connected. However, all of them should be covered by public data records, which should constitute an information resource.

3) The boundaries of basins and aquifers and the underground residue of these waters are generally worse known than the boundaries of surface water bodies and the 
underground residue of water within them. Lack of information often applies to both long aquifers and the so-called lenses, which are conditionally fed by water only as vertical, topdown. For example, in the state of Texas (USA), the owner of the land is allowed unlimited pumping of water within his ownership. He is supposed to pump water out of his "own" lens. Neighbors suffering from water shortages in their wells and boreholes may request that this pumping be restricted only if the court proves that the defendant is not using the "lens" but rather the flow of groundwater (the aquifer).

4) Groundwater is mainly run by the bodies responsible for the subsoil. Competence manifests itself mainly when they grant or deny groundwater use licenses to applicants. In Russia, there have been cases of illegal drilling of boreholes to the depth of artesian waters.

5) The aquifers of unfit water are often used to discharge bottom water (" aquiferscollectors). Literature underlines their tightness, making liquid waste disposal a reliable enough way to get rid of them.

All these peculiarities are quite sharply separated groundwater from the surface ones. They also lead to different economic measures, which are applied everywhere. At the same time, the experience of developed countries shows that it is groundwater that is primarily used as a source of drinking and domestic water supply.

Order of the Ministry of Natural Resources of Russia from 27.12.2016 № 679 "On Approval of the Classification of Aquifers (first, second and other aquifers)" allows enforcers to better understand the problem of groundwater.

The following classification is provided in top-down cut-off order from the earth's surface: the first aquifer located in a subsurface section first from the ground surface, located on a waterproofing aquifer; the second aquifer located in a subsurface section second from the ground surface, overlapped by a waterproofing aquifer and located on a waterproofing aquifer; the third and deeper aquifers, successively located below the second aquifer, separated by waterproofing aquifers.

By the presence or absence of a hydraulic connection with surface water bodies are classified as having a hydraulic connection with surface water bodies and having no hydraulic connection with them. By the possibility of using aquifers as centralized water supply sources, aquifers shall be classified as being used as centralized water supply sources or not used as such.

It should be noted that in Russia underground residue of groundwater is not used to the extent necessary for society, but it is already negatively affected. Therefore, well-designed use of subterranean water sources using resource-saving technologies and techniques is necessary. In this regard, it would be useful to develop contractual structures that provide a productive public-private partnership in the creation and operation in the subsoil of artificial reservoirs with groundwater suitable for use in various sectors of the economy. On the one hand, it is necessary to guarantee the interests of investors who create expensive infrastructure, and on the other hand, to protect and promote the public interest in the economic consumption of water. Some draft law developers propose to regulate this issue through licensing of subsoil use. However, this method of legal regulation puts the investor in dependence on state authorities.

Special measures include the construction of engineering structures to intercept polluted water in the case of its spill to localize sources of groundwater pollution, the creation of protective structures around the source of groundwater pollution, the elimination of sources of groundwater pollution, monitoring of the state of groundwater in contaminated areas.

To monitor the state of the groundwater and to take special measures for its protection on water abstractions of groundwater the production and reserve boreholes should be equipped with groundwater production meters and devices for measuring groundwater levels. In turn, water abstractions of groundwater with the volume of production over 100 
cubic meters per day should be equipped with monitoring boreholes for systematic observations of the quality and level of groundwater in the subsoil area provided for use.

Moreover, the location of observation boreholes and their design is determined regarding the geological and hydrogeological conditions of subterranean water bodies. Parameters of observation boreholes and groundwater monitoring conducted on them must be adjusted if the values of groundwater pollution indicators previously agreed in the design documentation are exceeded.

Design and construction of observation boreholes, monitoring of groundwater conditions, and laboratory control of groundwater quality are carried out by subsoil users and (or) other persons who own objects that are potential sources of harmful effects on groundwater based on ownership or any other legal basis.

\section{Discussion}

In case of deterioration in the quality of extracted groundwater, expressed more than mineralization, hardness, the appearance of bacterial and chemical contamination, as well as deviation of the water abstraction mode from the indicators specified in the project documentation, the subsoil user is obliged to notify the relevant territorial authority of Federal Service for Supervision of Natural Resource Usage within one day.

According to the rules of protection, groundwater is brought to the surface with a minimum number of catchment facilities. In the case of withdrawal of groundwater, which has aggressive corrosive effects, fracture-resistant materials are used for the manufacture of the production casing string and other structures. During drilling new production or exploratory boreholes within the field, as well as when performing any repair work on existing boreholes, measures are taken to prevent depressurization of casing string insulating various aquifers.

In general, subterranean water bodies are much less affected than surface rivers and lakes. However, in recent decades in Russia (as in other CIS countries) there has been an increase in pollution, contamination, and depletion of groundwater. This applies not only to such industrial centers as Moscow, St. Petersburg, Kursk. Falling groundwater levels affect such suburbs of the capital as Lyubertsy and Mytishchi.

The characteristics of groundwater are recorded in the data banks following the requirements of subsoil legislation. But to mutually coordinate the interests of subterranean water bodies, it is required to take into account also in the State Water Register.

According to the press, some enterprises voluntarily pump contaminated industrial wastewater into deep aquifers, thereby creating a threat to both groundwater and related rivers. The prosecutor's office and Federal Service for Ecological, Technological, and Nuclear Supervision through the court seeking to stop the injection of industrial effluents containing waste of the first hazard class (including mercury).

According to the Protection Rules, the disposal of associated (produced) water, radioactive waste, production, and consumption waste of $\mathrm{I}-\mathrm{V}$ hazard classes is possible in deep aquifers of rocks (reservoirs), including those containing highly mineralized and not using groundwater. The placement of wastewater associated (produced) water, liquid toxic, radioactive and other hazardous waste in rock formations containing groundwater that can be used for heat, power, industrial, drinking and domestic purposes is not allowed.

Protecting groundwater from contamination must be ensured not only during operations for drilling boreholes, producing groundwater, or eliminating boreholes. To an equal extent, it must be taken care of in using certain sections of the earth's surface (which hydrological connection with groundwater is not always obvious). If these areas are composed of permeable rocks, groundwater contamination may occur through them. 
That is why in some European countries, "sensitive" areas with permeable soils provide for significant restrictions on economic activity. Therefore, the disposal of dumps, as well as relatively "dirty" production enterprises, chemical storage facilities, gas stations, oil product storages, and other polluting facilities should be done in such a way as to exclude groundwater pollution. To select naturally protected sites suitable for "dirty" production, you need to have detailed maps of the geological structure of the earth's crust. The latter, however, is not drawn up for the entire territory of Russia, and those that are drawn up are not always accessible to those who should be guided by them.

The Water Strategy of Russia provides for the development of "requirements for the use of land within the boundaries of the groundwater deposits, which can be used for centralized drinking and domestic water supply". The water strategy of Russia thus implies the introduction of more stringent sanitary requirements for the owners of land (they are called "potuskules"), in which there is a through wetting of the soil with surface runoff, replenishing groundwater (in the literature, such sites are sometimes referred to as potuskules, from the Latin potus - drinking).

This plan, not yet reflected in any source of Russian law, deserves active support. It focuses on water protection activities that go beyond conventional water protection or nature protection activities. However, in the Water Strategy of Russia, the solution to this problem is facilitated without taking into account some facts. Not all of the land sites mentioned above are identified, outlined, and entered into state data banks. There is no procedure for recognizing the relevant sites as "responsible" for the replenishment and cleanliness of groundwater. It is not known which state body should monitor compliance with the increased sanitary and nature protection (water protection) standards addressed to the owners of these sites.

Thus, the protection of groundwater from pollution requires the development of a set of legal rules governing the identification and official recognition of potuskules, fixing their borders on plans and the ground, imposing restrictions on their owners in economic and other activities.

The "natural closeness" of groundwater does not preclude the spread to them of some specific types of water management activities. Over the past decades, in some countries, including Russia, such a specific water management technique as artificial replenishment of groundwater due to a surface runoff - artificial recharge has spread, for example, the Arzamas Vodokanal has long been using this method of replenishing underground residues. To do this, special pools are filled with surface water, from which it seeps into aquifers. Places for pools are selected taking into account the high permeability of soils. This method is possible only if the terrain is relatively "free". But if it is already built up, and not suitable facilities, then the organization of artificial recharge is difficult or even impossible.

Similar approaches of the legislator are valid in such a European country as the Republic of Croatia. The Government of Croatia has adopted a River Basin Management Plan, an important component of which is the Description of the main characteristics and conditions of waters. In the Description, along with surface waters, the main characteristics, locations, and boundaries, as well as the state of groundwater (including an assessment of the degree of pollution) are entered. Among the main tasks, the legislator of this country considers the gradual reduction of groundwater pollution, provides for the Government of Croatia to prescribe the groundwater quality standard (along with surface, territorial waters).

Within the coastal territories, groundwater (along with surface waters) are often included by the Croatian legislator in the category of coastal waters, which are intensively used in the Croatian economy.

In chapter 26 of the Criminal Code of the Russian Federation, 18 compositions of ecological crimes are formulated, providing liability for attacks on the environment as a 
whole (are general - Art. 246-248) and for special ecological crimes (encroach on individual objects (components, parts of nature) - Art. 249-262).

General ecological crimes infringe on the environmental safety of both the environment as a whole and the population.

Special ecological crimes cause damage to certain objects (components) of the environment: atmospheric air, soil, surface or groundwater, flora or fauna, etc. Special ecological crimes are, for example, water pollution.

In many cases of committing ecological crimes of a general nature, the harm is also caused to certain components of nature. Thus, a violation of the rules of environmental protection during the performance of work may entail damage to the land, water pollution, death of vegetation, etc.

Dispositions of all articles on responsibility for ecological crimes are blank and refer to various laws and by-laws, which formulate environmental safety requirements requirements for the protection of water bodies.

To prevent and eliminate pollution of water bodies, the sources of their pollution are determined. Sources of pollution are recognized as objects (stationary and others) from which hazardous substances are discharged or otherwise transferred to water bodies that impair the quality of surface and groundwater, restrict their use, and also adversely affect the state of the bottom and banks of water bodies.

So, the Criminal Code of the Russian Federation establishes criminal liability for water pollution (Art. 250): pollution, clogging, depletion of surface or groundwater, sources of drinking water supply or any other change in their natural properties, if these acts have caused substantial harm to the animal or plant world, fish stocks, forestry or agriculture (part 1).

The main immediate object of this crime is public relations in the field of ensuring environmental safety, protection, and rational use of water. Optional - relationship to protect human life and health.

Crime subject - is surface or groundwater, sources of drinking water supply.

The objective side of the crime is the pollution, clogging, depletion of surface or groundwater, sources of drinking water supply or otherwise changing their natural properties by action or inaction.

Pollution of water bodies - discharge or other entry into water bodies, as well as the formation of harmful substances in them, which, when dissolved, impair the quality of surface and groundwater, limit their use, or adversely affect the state of the bottom and banks of water bodies.

Clogging - is a discharge or otherwise entering into water bodies of insoluble or poorly soluble in water objects or suspended particles that worsen the condition and make drinking water use difficult.

Water depletion - is a steady reduction in residues with deterioration in the quality of surface and groundwater (Art. 1 of the Water Code of the Russian Federation).

Under another change in the natural properties of water is understood any other change in their physical, chemical, or biological properties.

Particularly qualifying feature in Part 3 of Art. 250 of the Criminal Code of the Russian Federation: the negligence of the death of a person (one or more) as a result of the acts specified in parts 1 and 2 of this article.

The components of administrative misconduct, consisting of water pollution, according to the characteristics of the objective side are similar to the wording used in Art. 250 of the Criminal Code of the Russian Federation. However, they are all designed as "threat compounds" (that is, formal) and provide for liability for acts that may entail consequences in the form of pollution, clogging, or depletion of water. 
So, part 4 of Art. 8.42 Administrative Code of the Russian Federation (Violation of the special mode for carrying out economic and other activities on the coastal protective strip of a water body, water protection zone of a water body or the mode for carrying out economic and other activities in the sanitary protection zone of sources of drinking and domestic water supply) provides for liability for the use of the territory of the first belt zones of sanitary protection of sources of drinking and domestic water supply in violation of sanitary and epidemiological requirements. Decision No. 12-2141/2019 of June 26, 2019, in record case No. 12-2141/2019 of the Krasnodar Regional Court (Krasnodar Territory) established that the municipal unitary enterprise "Vodokanal of Novorossiysk" used the sanitary protection zones of the first belt of drinking and domestic water supply of water abstraction at natural springs in violation of the restrictions established by sanitary rules and norms by legislation on the sanitary and epidemiological welfare of the population. In this zone, planting of tall trees was allowed, which can lead to depletion and pollution of groundwater, as a result of which it will become impossible to use it for drinking and domestic use.

\section{Conclusion}

Summarizing the results of the study on the legal status of subterranean water bodies, we can highlight the main approaches to the legal regulation of relations in connection with groundwater:

private character dating back to the days of Roman law. Accordingly, land ownership extends to waters that can be found in the subsoil, so that the respective owner is free to extract and use them, even if damage has been caused to a third party. This broad permissiveness, which was seen as a manifestation of the theory of abuse of the right as private nature of groundwater: its owner was the owner of the land. This was also the application of the Roman concept of ownership, in which the owner of the land was not only above the surface but also above the sky and subsoil;

water exploration and exploitation character. The ipsoiure right of the landowner, recognized under the civil legislation, was limited to drinking and domestic use to use groundwater found on his land. For any other use of water, it was obligatory to obtain the relevant permit;

administrative nature inherent in the legal order of the 19th-20th centuries. State bodies, institutions, and organizations shall be granted the right to investigate and dig in private and national lands the ownership of which has been transferred to a private person to obtain groundwater. The right of the owner of the land, that stores water, to compensation for the damage arising from the implementation of such works was recognized;

Step by step, a conceptual (with an environmental focus) approach was developed for a benefit such as groundwater: conceptualization and general concepts; the origin of exploitation rights; protection and limitation of exploitation; collective management of groundwater rights. Continuous development of the groundwater status: a) exploration for groundwater (in private property and national assets); b) exploitation of groundwater (general provisions; protection zones; exploitation restrictions; groundwater communities; change of collection and/or recovery location; change in the source of supply; alternative collection and/or recovery points; artificial residues; special provisions).

\section{References}

1. V.B. Agafonov, Legal regulation of environmental protection and provision of ecological safety at subsurface use: monograph (Prospect, M., 2012) 
2. S.A. Bogolyubov, Realization of the property rights for natural resources: monograph (Institute of Legislation and Comparative Law under the Government of the Russian Federation. Lawyer, M., 2007)

3. S.A. Bogolyubov, E.A. Galinovskaya, Yu.G. Zharikov et al., Institutes of ecological law. Institute of legislation and comparative legal studies under the government of the Russian Federation. Scientific (Exmo, M., 2010)

4. Yu.A. Tikhomirov, T.Ya. Khabrieva, Concepts of the Russian Legislation Development (Institute of Legislation and Comparative Law under the Government of the Russian Federation, Moscow, 2014)

5. L.A. Zaslavskaya, Scientific notes of All-Union Scientific Research Institute of Soviet Legislation 18, 73-85 (1969)

6. O.S. Kolbasov, Theoretical foundations of the right to use water in the USSR. Monograph/Academy of Science of the USSR. Institute of State and Law (Science, M., 1972)

7. E.N. Mukhina, Agricultural and land law 12, 77-88 (2010)

8. E.N. Mukhina, Agrarian and land law 6, 47-50 (2011)

9. N.I. Plotnikov, Groundwater - our wealth. 2nd ed., revised and expanded (Nedra, Moscow, 1990)

10. Melioration and water economy 1, 38-39 (1990)

11. D.O. Sivakov, Legislation and economics 6, 77-80 (2005)

12. D.V. Khaustov, Ecological law of Russia. Collection of materials of scientific-practical conferences 5, 567-576 (2009)

13. N.V. Belotelov, Proceedings of Institute for System Analysis of Russian Academy of Sciences 68(2), $16-21$ (2018)

14. V.A. Minaev, V.A. Ivanov, A.I. Zhavoronkov, Service in Russia and abroad 8.4(51), $81-93(2014)$ 